\title{
Structure and decay of a proto-Y region in Tilapia, Oreochromis niloticus
}

\author{
William J Gammerdinger ${ }^{1}$, Matthew A Conte ${ }^{1}$, Enoch A Acquah ${ }^{1}$, Reade B Roberts ${ }^{1,2}$ and Thomas D Kocher ${ }^{1 *}$
}

\begin{abstract}
Background: Sex-determination genes drive the evolution of adjacent chromosomal regions. Sexually antagonistic selection favors the accumulation of inversions that reduce recombination in regions adjacent to the sex-determination gene. Once established, the clonal inheritance of sex-linked inversions leads to the accumulation of deleterious alleles, repetitive elements and a gradual decay of sex-linked genes. This in turn creates selective pressures for the evolution of mechanisms that compensate for the unequal dosage of gene expression. Here we use whole genome sequencing to characterize the structure of a young sex chromosome and quantify sex-specific gene expression in the developing gonad.

Results: We found an $8.8 \mathrm{Mb}$ block of strong differentiation between males and females that corresponds to the location of a previously mapped sex-determiner on linkage group 1 of Oreochromis niloticus. Putatively disruptive mutations are found in many of the genes within this region. We also found a significant female-bias in the expression of genes within the block of differentiation compared to those outside the block of differentiation. Eight candidate sex-determination genes were identified within this region.

Conclusions: This study demonstrates a block of differentiation on linkage group 1, suggestive of an $8.8 \mathrm{Mb}$ inversion encompassing the sex-determining locus. The enrichment of female-biased gene expression inside the proposed inversion suggests incomplete dosage compensation. This study helps establish a model for studying the early-tointermediate stages of sex chromosome evolution.
\end{abstract}

\section{Background}

The classic model of sex chromosome evolution begins with the emergence of a new sex- determining gene on an autosome [1]. The new sex-determiner may be linked with genes experiencing sexually antagonistic selection. Selection favors mechanisms, such as chromosomal inversions, that reduce recombination between the sex-determination locus and sexually antagonistic genes [2,3]. The human sex chromosomes have undergone at least four such inversions, which may have limited recombination between the sex-determination locus and nearby sexually antagonistic genes [4].

Inversions create a clonally inherited chromosomal segment with a relatively small effective population size when compared to the rest of the genome [5]. Sex chromosomes therefore become a haven for deleterious mutations and repetitive elements that are difficult to

\footnotetext{
* Correspondence: tdk@umd.edu

'Department of Biology, University of Maryland, College Park, MD 20742, USA Full list of author information is available at the end of the article
}

purge. These deleterious mutations accumulate via Muller's Ratchet, as well as by hitchhiking with advantageous mutations $[6,7]$. Degradation of functional genes on the Y- or W-chromosome leaves the homogametic sex carrying two functional copies of a particular gene, while the heterogametic sex carries only one functional copy. Therefore, mechanisms are needed to maintain appropriate expression of dosage-sensitive genes on emerging sex chromosomes [8-10]. In mammals, global dosage compensation is accomplished through $\mathrm{X}$-inactivation [10,11]. However, in many species, dosage compensation is partial and the expression of many genes is not compensated [8].

Some sex-determining genes are conserved for long periods of time. An example is $S r y$, a gene that has controlled sex-determination in therian mammals for approximately 180 million years [7,12-14]. Other sex-determination genes hold sway for much shorter periods of time. There have been at least five transitions in the mechanism controlling sex-determination in rice fish (genus Oryzias) during the last 20 million years [15]. Similarly rapid rates of sex 
chromosome evolution have been identified among sticklebacks (Family Gasterosteidae) [16].

The evolution of new sex-determination genes may have contributed to the rapid radiation of African cichlid fishes [17]. Among the closely related haplochromine cichlids of Lake Malawi, sex-determination regions have been localized to linkage groups 3 (ZW), 5 (ZW), 7 (XY) and 20 (XY) [18-20]. Among tilapia cichlids, sex-determination regions have been localized to linkage groups 1 (XY), 3 $(\mathrm{ZW})$ and $23(\mathrm{XY})$ [21,22]. Multiple sex-determination genes often segregate within a single species $[18,23]$. The blue tilapia, Oreochromis aureus, segregates both an XY system on linkage group 1 and a ZW system on linkage group 3 [23]. Some strains of the Nile tilapia, O. niloticus, have an XY system on linkage group 1, while others segregate an XY system on linkage group $23[22,24,25]$.

The goal of this study was to characterize the sexdetermination locus on linkage group 1 in O. niloticus. We took a family-based strategy, separately pooling males and females from two crosses, and performing whole genome sequencing on the pooled DNAs. We cataloged the density and frequency of single nucleotide polymorphisms (SNPs) and assessed their functional impact. We identified an $8.8 \mathrm{Mb}$ block of differentiation suggestive of a Y-linked inversion on linkage group 1 . We found high densities of functionally significant SNPs within this differentiated block. Analysis of gonadal transcriptomes demonstrated an enrichment of female-biased gene models within the inversion, which suggests that dosage compensation is incomplete in this strain of $O$. niloticus.

\section{Results and discussion}

\section{Sequencing of male and female DNA pools}

We obtained $\sim 202$ million reads from the pool of male DNA and 219 million reads from the pool of female DNA. $90.12 \%$ of the male and $90.67 \%$ of the female reads were aligned to the $O$. niloticus reference genome. Genome-wide coverage was slightly lower in males (32.97, standard deviation $=24.41$ alignments per site), compared to females (36.68, standard deviation $=31.39$ alignments per site).

\section{Large block of divergence on linkage group 1}

The mean $\mathrm{F}_{\mathrm{ST}}$ between the male- and female-pooled genomes at polymorphic sites over the entire genome was 0.0356 (standard deviation $=0.030$ ). A region between 10.1 $\mathrm{Mb}$ and $18.9 \mathrm{Mb}$ on linkage group 1 showed a substantially higher value of $\mathrm{F}_{\mathrm{ST}}=0.0807$ (standard deviation = 0.061) (Figures 1a, and 2a). This region corresponds to the previously mapped sex-determination region in this strain of O. niloticus [21,24-27]. Mean read coverage within the differentiated region was lower in males $(34.65$, standard deviation $=10.56)$, compared to females $(38.45$, standard deviation $=12.00$ ), but this difference was consistent with the total number of reads obtained from each sex. We used Fisher's exact test to determine whether the allele frequency of SNPs was significantly different between males and females. We found a cluster of highly significant SNPs within the differentiated block on linkage group 1 (Figures $1 \mathrm{~b}$, and $2 \mathrm{~b}$ ).

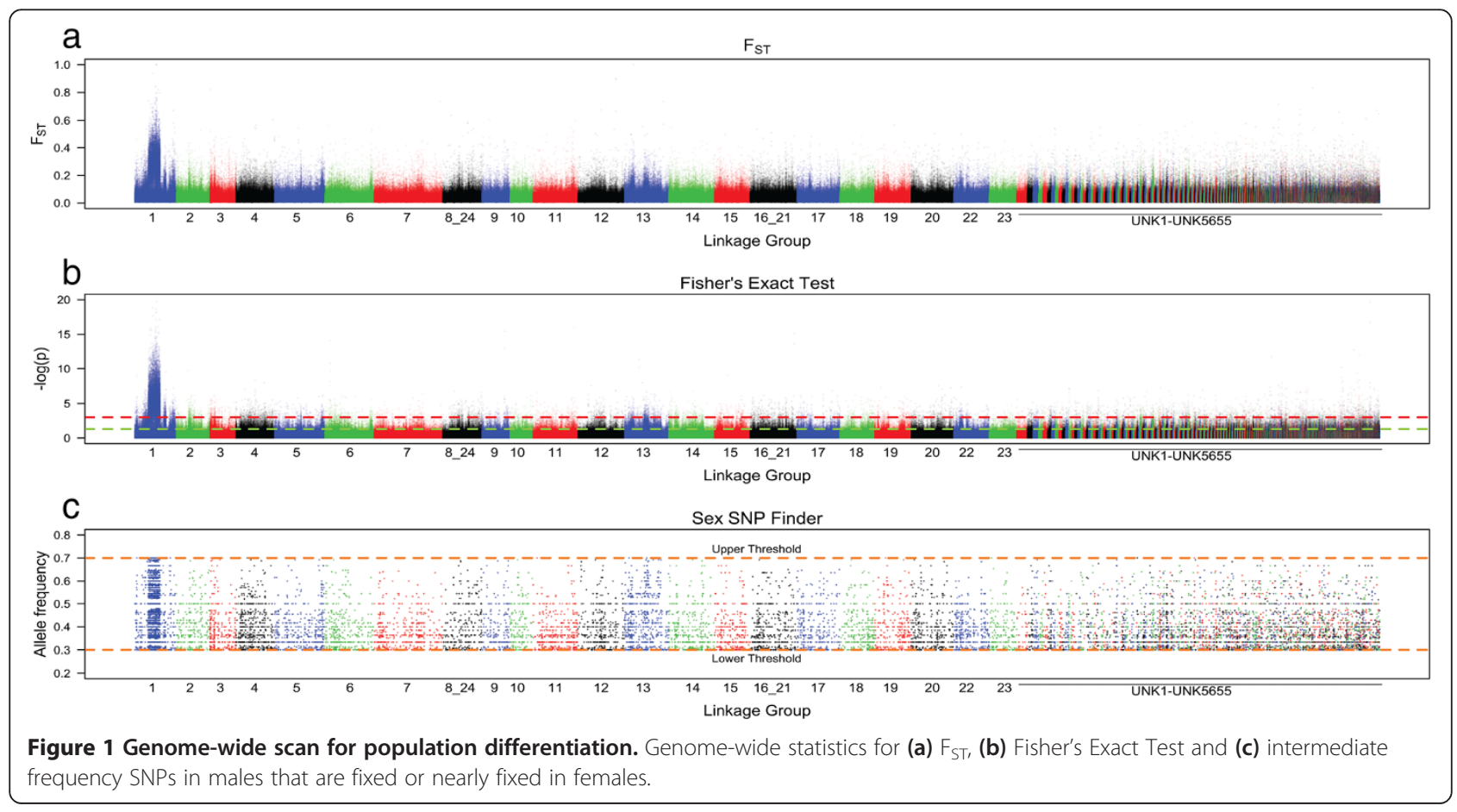



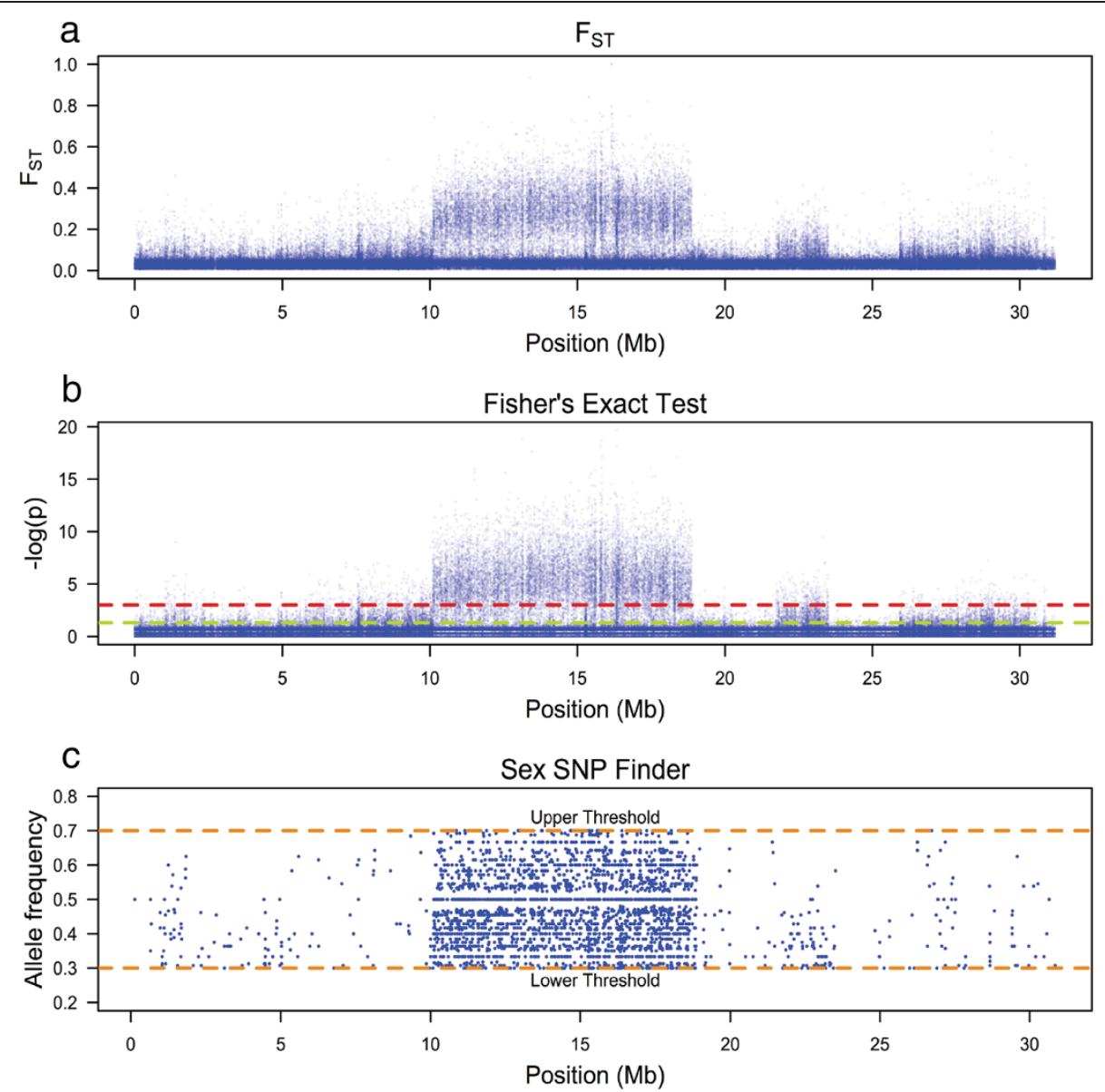

Figure 2 Population differentiation on linkage group 1. Differentiation statistics for linkage group 1. (a) $F_{S T}$ (b) Fisher's Exact Test and (c) intermediate frequency SNPs in males that are fixed or nearly fixed in females.

We also counted the number of positions per $10 \mathrm{~kb}$ window that were fixed in female pools and had a SNP in intermediate frequency in male pools, as would be consistent with females having two $\mathrm{X}$ chromosomes and males having an $\mathrm{X}$ and a $\mathrm{Y}$ chromosome, using Sex_SNP_finder_now.pl. There were 40,514 of these SNPs found across the genome. $18,277(2,076.932 / \mathrm{Mb})$ lay inside the differentiated block and 22,237 (24.197/Mb) lay outside. Among the 300 nonoverlapping $10 \mathrm{~kb}$ windows with the highest frequency of these SNPs, 290 were found within the differentiated block on linkage group 1. The mean number of such SNPs per window was 21.81 (standard deviation $=13.84$ ) within the differentiated block and only 0.33 (standard deviation = 1.29) outside of this region (Figures 1c, and 2c). The elevated $\mathrm{F}_{\mathrm{ST}}$, along with the abundance of intermediate frequency SNPs in males that are fixed in females, suggests that this region has limited, if any, recombination between the $\mathrm{X}$ and $\mathrm{Y}$ alleles.

We considered the possibility that this block of differentiation is an artifact of the process by which we selected individuals for sequencing. We initially screened individuals by genotyping two sex-linked microsatellites in order to confirm family identity and sex. We required males to demonstrate a heterogametic pattern and females to demonstrate a homogametic pattern for both markers. Five male and five female individuals were excluded by these criteria and may represent naturally sexreversed individuals. The sharply defined edges of the block lie 4.22 $\mathrm{Mb}$ upstream and $3.37 \mathrm{Mb}$ downstream of the microsatellites we genotyped (Figures 1 and 2), which would normally represent approximately $5 \mathrm{cM}$ of genetic distance in this species [28]. However, there is no evidence of an exponential decay of $\mathrm{F}_{\mathrm{ST}}$ in the flanking regions as would be expected if there was recombination between the markers and the edges of the block. We also considered the possibility that the high level of differentiation might be due to an $8.8 \mathrm{Mb}$ duplication on the Y. However, the depth of read coverage is relatively consistent across this entire linkage group. Additionally, cytogenetic studies have not revealed any evidence of heteromorphy in this chromosome pair as would arise from a translocation [29]. The sum of the evidence 
suggests that this block of differentiation most likely reflects an $8.8 \mathrm{Mb}$ inversion on the Y-chromosome.

The relatively small size of the putative inversion, and its location in the middle of the chromosome, make it challenging to characterize using standard cytogenetic techniques. Ideally, we would characterize the breakpoints, but we were unable to identify anomalous Illumina mate pairs near the ends of the inversion in our short insert libraries. Longer reads or more widely spaced mate pairs will be needed to characterize the breakpoints of the proposed inversion.

\section{Functionally significant SNPs}

We examined the functional consequences of the SNPs that were fixed in female pools but at intermediate frequency in male pools at the same position using SnpEff and SnpSift [30,31]. Within the $8.8 \mathrm{Mb}$ differentiated block we found 13 stop codon changes $(1.477 / \mathrm{Mb}), 3$ start codon losses $(0.341 / \mathrm{Mb})$ and 2 splice site alterations $(0.227 / \mathrm{Mb}$, Table 1). In the remaining $919 \mathrm{Mb}$ of the genome we found a total of 9 stop codon changes $(0.010 / \mathrm{Mb})$, no start codon losses, and 3 splice site alterations $(0.003 / \mathrm{Mb}$, Additional file 1). SNPs classified as non-synonymous coding changes by SnpEff totaled $168(19.091 / \mathrm{Mb})$ within the differentiated region and $147(0.160 / \mathrm{Mb})$ across the rest of the genome (Additional file 2).

The elevated density of high impact SNPs within the proposed inversion leads us to believe that deleterious alleles have begun to accumulate on this proto-Y. This is in accordance with the canonical model of heterogametic sex-chromosome evolution [2,32] and empirical observations of the therian mammal Y-chromosome, Silene, Drosophila and tongue sole [4,33-35].

\section{Localization of the sex-determining gene}

Previous studies have concluded that sex is multifactorial in O. niloticus $[24,36]$ with a major sex-determination gene on LG1 [21]. Our study confirms this previous work, identifying an $\mathrm{XY}$ sex-determination locus in the middle of LG1 (Figure 3). The sex-determination gene was first

Table 1 Putative functional mutations in the proposed inversion

\begin{tabular}{|c|c|c|c|c|c|c|c|}
\hline Gene name & $\begin{array}{l}\text { SNP location } \\
\text { on LG1 }\end{array}$ & $\begin{array}{l}\text { Reference } \\
\text { codon }\end{array}$ & $\begin{array}{l}\text { SNP } \\
\text { codon }\end{array}$ & $\begin{array}{l}\text { Effect on } \\
\text { the } Y\end{array}$ & $\begin{array}{l}\text { Effect on } \\
\text { the } X\end{array}$ & $\begin{array}{l}\text { Frequency of } \\
\text { SNP in males }\end{array}$ & $\begin{array}{l}\text { Frequency of } \\
\text { SNP in females }\end{array}$ \\
\hline Ras-related protein R-Ras2 (LOC100693950) & 10506882 & CGA & TGA & Stop Gain & - & 0.462 & 0 \\
\hline Signal peptide & 10868192 & TCA & $\mathrm{TGA}$ & - & $\begin{array}{l}\text { Stop } \\
\text { Gain }\end{array}$ & 0.545 & 1 \\
\hline AMP deaminase 3 (LOC100694225) & 11096201 & TGA & $\mathrm{TCA}$ & Stop Lost & - & 0.454 & 0 \\
\hline Zinc finger protein 821 (LOC100712266) & 12466312 & ATG & $A C G$ & Start Lost & - & 0.4 & 0 \\
\hline Zinc finger protein 821 (LOC100712266) & 12466313 & ATG & ATA & Start Lost & - & 0.4 & 0 \\
\hline $\begin{array}{l}\text { SAFB-like transcription modulator } \\
\text { (LOC100711186) }\end{array}$ & 12619332 & CGA & TGA & - & $\begin{array}{l}\text { Stop } \\
\text { Gain }\end{array}$ & 0.613 & 1 \\
\hline Hepatic lipase (Lipc) & 12690753 & TGA & CGA & Stop Lost & - & 0.448 & 0 \\
\hline $\begin{array}{l}\text { Ammonium transporter Rh type C } 2 \\
\text { (LOC100706367) }\end{array}$ & 13529856 & ATG & ATA & - & Start Lost & 0.575 & 1 \\
\hline AFG3-like protein 1 (LOC100702885) & 13725056 & TTA & $\mathrm{TGA}$ & Stop Gain & - & 0.439 & 0 \\
\hline $\begin{array}{l}\text { CUB and sushi domain-containing protein } 1 \\
\text { (LOC100698036) }\end{array}$ & 15189214 & CAA & TAA & Stop Gain & - & 0.391 & 0.027 \\
\hline $\begin{array}{l}\text { CUB and sushi domain-containing protein } 1 \\
\text { (LOC100698036) }\end{array}$ & 15243948 & TGC & TGA & Stop Gain & - & 0.391 & 0 \\
\hline Neuromedin-K receptor (LOC100693904) & 15788009 & CAGG & CAGC & $\begin{array}{l}\text { Splice Site } \\
\text { Acceptor Lost }\end{array}$ & - & 0.343 & 0 \\
\hline Protein FAM176A (LOC100700039) & 16417062 & CGA & TGA & Stop Gain & - & 0.475 & 0 \\
\hline $\begin{array}{l}\text { GC-rich sequence DNA-binding factor } \\
\text { (LOC100700589) }\end{array}$ & 16480688 & CAGA & CAGG & $\begin{array}{l}\text { Splice Site } \\
\text { Acceptor Gain }\end{array}$ & - & 0.512 & 0.018 \\
\hline $\begin{array}{l}\text { BTB/POZ domain-containing protein KCTD3 } \\
\text { (LOC100703295) }\end{array}$ & 16809270 & CGA & TGA & Stop Gain & - & 0.52 & 0 \\
\hline Hypothetical protein (LOC100705710) & 17489648 & CAA & TAA & - & $\begin{array}{l}\text { Stop } \\
\text { Gain }\end{array}$ & 0.452 & 0.97 \\
\hline Hypothetical protein (LOC100705710) & 17507222 & TAA & CAA & Stop Lost & - & 0.469 & 0.04 \\
\hline Nuclear factor of activated T-cells & 18194412 & $\mathrm{TGG}$ & TGA & - & $\begin{array}{l}\text { Stop } \\
\text { Gain }\end{array}$ & 0.5 & 0.982 \\
\hline
\end{tabular}




\section{Linkage Group 1 XY Locus}

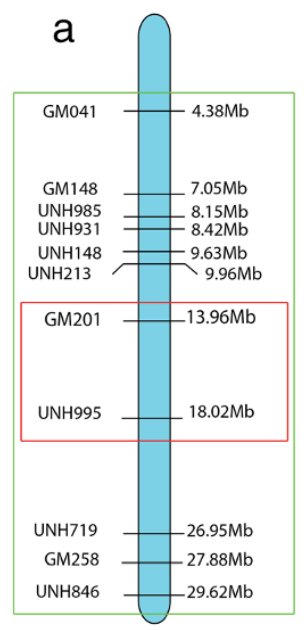

Lee et al., 2003

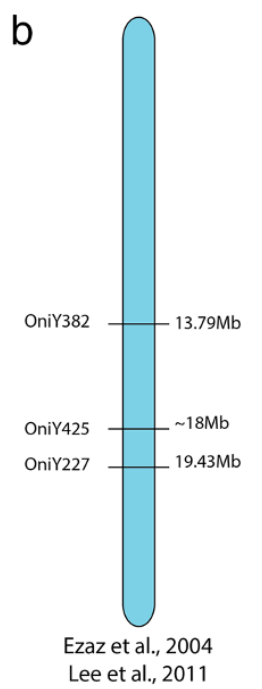

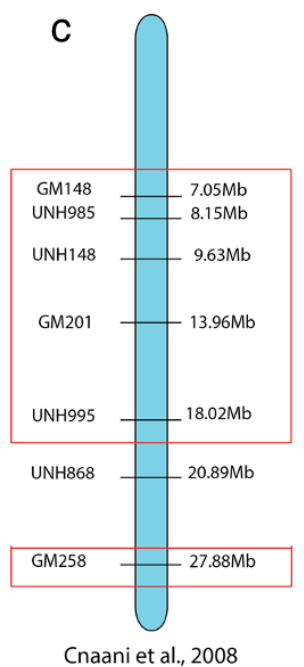

Cnaani et al., 2008

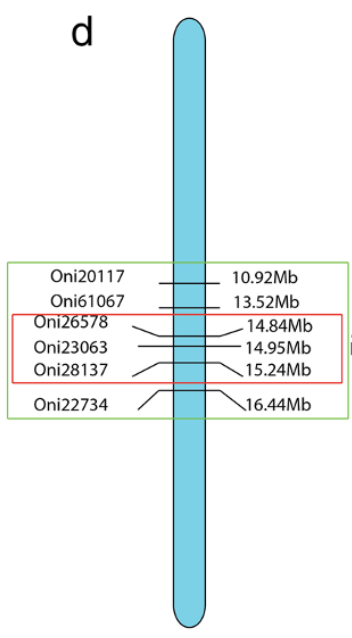

Palaiokostas et al., 2013

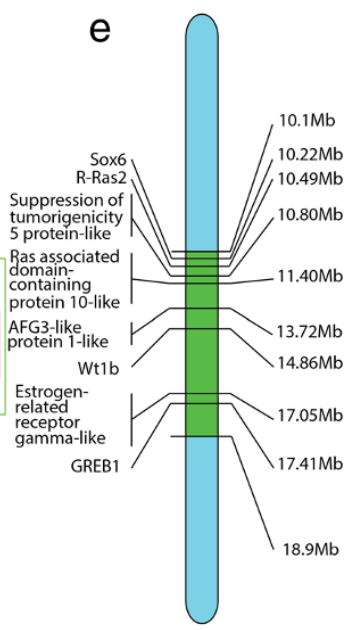

Proposed Inversion Model

Figure 3 Mapping of sex-determination locus on linkage group 1. Previous studies identifying sex-linked markers on LG1. (a) Lee et al., [24] used a bulked segregant analysis. The green rectangle surrounds markers that were significantly sex-associated. The red rectangle encompasses the region with the highest significance. (b) Ezaz et al., [26] identified three Y-specific AFLPs. OniY425 was assigned through BLAST to scaffold UNK43. It was placed on LG1 according to Lee et al., [25], which used BAC contigs to place it within $100 \mathrm{~kb}$ of UNH995. (c) Cnaani et al., [21], also used a bulked segregant analysis. The markers within the red rectangles indicate markers that were significantly associated with sex. (d) Palaiokostas et al., 2013, identified sex-linked RAD-Seq markers. The green rectangle encompasses the markers with a LOD score greater than 15, while the red rectangle encloses the markers flanking the marker with the highest LOD score (Oni23063 with a LOD score of 18.5). (e) Proposed inversion in green with the eight candidate genes discussed in this paper.

mapped near microsatellite markers GM201 (13.96 Mb) and UNH995 (18.02 Mb, Figure 3a) [24]. Additional AFLP and FISH mapping found sex-associated markers at $13.79 \mathrm{Mb}$, near $18 \mathrm{Mb}$ and at $19.43 \mathrm{Mb}$ (Figure 3b) $[25,26]$. Another study confirmed GM201 and UNH995 along with several other sex-associated markers spanning a region from $7.05 \mathrm{Mb}$ to $18.02 \mathrm{Mb}$ (Figure 3c) [21]. Lastly, a RAD-seq experiment found the highest associations at $14.95 \mathrm{Mb}$ (LOD score 18.5), but demonstrated a broad region spanning $10.92 \mathrm{Mb}$ to $16.44 \mathrm{Mb}$ with a LOD score above 15 (Figure 3d) [27].

The multifactorial nature of sex-determination in this species causes difficulties for genetic mapping studies. An $\mathrm{XX}$ individual may develop as a male due to other genetic factors, or environmental effects on differentiation. These individuals would appear to be recombinant in the sex interval. We previously claimed to exclude Wilm's tumor protein homolog $(\mathrm{Wt1b})$ as the sex-determining gene on the basis of two recombinant individuals [37], but this conclusion is now in doubt. Conversely, the absence of recombination within the proposed inversion may preclude any further fine-mapping of the gene responsible for sex-determination.

\section{Differences in gene expression}

The block of differentiation on linkage group 1 comprises just more than $1 \%$ of the assembled genome and contains
257 RefSeq annotated genes. Cufflinks predicted 234 gene models within the block of differentiation and predicted 22,411 gene models across the entire transcriptome. Of the gene models that showed an FPKM of $>0.05$ in at least one sex, 7,977 gene models (37.4\%) showed higher expression in males, while 13,375 (59.7\%) gene models showed higher expression in females. Furthermore, within the inverted region, only 68 of these gene models (29.6\%) showed a male bias (Additional file 3), while 162 of these gene models (69.2\%) showed a female bias (Additional file 4). The enrichment of female biased gene models within the proposed inversion is significant $\left(X^{2}=5.58\right.$, $\mathrm{p}<0.05)$. These data suggest that this sex chromosome is at an early-to-intermediate evolutionary phase where the degradation of a proto-Y has begun and expression of Y-linked genes in males is reduced. However, mechanisms for complete dosage compensation have yet to take hold.

\section{Candidate sex determiners}

Since the proposed inversion limits further attempts to fine-map the sex-determination gene, we evaluated candidate genes based upon putative functional polymorphisms, differential expression and prominence in pathways considered critical to sex-determination in other species. The complete list of candidate genes is presented in Table 2.

First, we analyzed all SNPs that SnpEff classified as high impact mutations (Table 1). One prominent candidate 
Table 2 Candidate genes in the proposed inversion

\begin{tabular}{|c|c|c|c|c|c|c|c|}
\hline Gene name & $\begin{array}{l}\text { Gene location } \\
\text { on LG1 (Mb) }\end{array}$ & $\begin{array}{l}\text { SNP location } \\
\text { on LG1 }\end{array}$ & $\begin{array}{l}\text { Coding } \\
\text { change }\end{array}$ & $\begin{array}{l}\text { Pool frequency } \\
\text { in males }\end{array}$ & $\begin{array}{l}\text { Pool frequency } \\
\text { in females }\end{array}$ & $\begin{array}{l}\text { Male } \\
\text { FPKM }\end{array}$ & $\begin{array}{l}\text { Female } \\
\text { FPKM }\end{array}$ \\
\hline Transcription factor SOX-6 (LOC100694759) & $10.22-10.30$ & 10295869 & T789K & 0.3684 & 1 & 3.56951 & 4.24045 \\
\hline Ras-related protein R-Ras2 (LOC100693950) & $10.48-10.51$ & 10506882 & R94STOP & 0.4615 & 0 & 6.78248 & 5.16947 \\
\hline $\begin{array}{l}\text { Suppression of tumorigenicity } 5 \\
\text { protein (LOC100693420) }\end{array}$ & $10.80-10.85$ & - & - & - & - & 7.41571 & 2.09969 \\
\hline $\begin{array}{l}\text { Ras association domain-containing } \\
\text { protein } 10 \text { (LOC100693148) }\end{array}$ & $11.40-11.41$ & - & - & - & - & 0.252165 & 0.0688204 \\
\hline AFG3-like protein 1 (LOC100702885) & $13.72-13.73$ & - & - & - & - & 3.35696 & 0.36143 \\
\hline Wilms tumor protein homolog (LOC100701078) & $14.86-14.88$ & 14873730 & $\mathrm{~A} 237 \mathrm{~V}$ & 0.4545 & 0 & 22.5644 & 13.2172 \\
\hline $\begin{array}{l}\text { Estrogen-related receptor gamma } \\
\text { (LOC100704106) }\end{array}$ & $17.05-17.11$ & 17093619 & $\mathrm{R} 172 \mathrm{H}$ & 0.4333 & 0.06 & 0.370072 & 0.105597 \\
\hline $\begin{array}{l}\text { Growth regulation by estrogen in breast cancer } \\
1 \text { (GREB1) }\end{array}$ & $17.41-17.42$ & 17424470 & R1775C & 0.5333 & 0.0571 & 0.961782 & 0.65826 \\
\hline
\end{tabular}

Sex-determination candidate genes within the proposed inversion with any codon changes and their FPKM values.

within the proposed inversion is Ras-related protein $R$ Ras2 (10.49 Mb-10.51 Mb), which is part of the Ras-MEKERK pathway within the TGF- $\beta$ signaling network [38]. Alterations to the TGF- $\beta$ network have been suggested as the mechanism for sex-determination in several fish species [15]. Ras2 has been implicated as particularly important in the proliferation of cells [39] and is expressed during early development in a hermaphroditic fish, Kryptolebias marmoratus [40]. Ras-related protein R-ras 2 has a stop codon gain in intermediate frequency in males that is absent in females. Disruption of R-ras 2 could lead to decreased cell proliferation of primordial germ cells, resulting in increased likelihood of maleness [15,39].

Next, we evaluated SNPs that SnpEff categorized as missense mutations (Additional file 2). The first of these candidate genes is Wilms tumor protein homolog, Wt1b (14.86 Mb-14.88 Mb), which has been implicated in gonadal development and acts directly upstream of $A M H$, the sex-determination gene in Odontesthes hatcheri [41]. $W t 1 b$ has also been demonstrated to bind to DNA and upregulate the sex-determination gene Sry in mammals. There is an $\mathrm{A} 237 \mathrm{~V}$ missense mutation in Wt1b that is absent in females and in intermediate frequency in males. Although our previous paper rejected $W t 1 b$ on the basis of two recombinant individuals [37], in light of the proposed inversion, we now believe that these individuals represented instances of natural sex reversal, not recombination.

A third candidate gene is estrogen-related receptor gamma, ERRY (17.05-17.11 Mb). It has a R172H missense mutation within a predicted DNA-binding domain [42]. ERR $\gamma$ has been shown to be a transcriptional activator of $D A X-1$, and $D A X-1$ has been implicated as having an antagonistic effect to Sry in mammals [43]. Therefore, a mutation in the DNA-binding domain of
$E R R \gamma$ could reduce $D A X-1$ transcription and thus have a masculinizing effect.

Growth regulation by estrogen in breast cancer 1 (GREB1) is another candidate gene (17.41-17.42 Mb) with a missense mutation. The $\mathrm{R} 1775 \mathrm{C}$ mutation alters the side chain from a basic side chain to a polar side chain. GREB1 has been shown to be predominantly expressed within ovaries of young mice [44]. Additionally, GREB1 has been demonstrated to be a coactivator of estrogen receptor- $\alpha$ [45]. Therefore, the missense mutation in GREB1 could downregulate the expression of estrogen receptor- $\alpha$, resulting in a masculinizing effect on the developing embryo.

Another potential sex-determination gene is transcription factor SOX-6 (10.22 Mb-10.30 Mb). There is a T789K missense mutation in intermediate frequency in males that is fixed in females and changes a polar side chain into a basic one. SOX-6 protein is localized to the same nuclear speckles as Sry and it has been suggested that it might play a role in sex-specific splicing in mammals [46].

We also evaluated gene models showing differential expression between males and females (Additional files 3 and 4). AFG3(ATPase Family Gene 3)-like protein 1 (13.72 $\mathrm{Mb}-13.73 \mathrm{Mb}$ ) has over a nine-fold male-biased expression. It is also on the list of SNPs with high impact coding alterations with a stop codon gain. However, a clear tie to sex-determination has yet to be elucidated.

Suppression of tumorigenicity 5 protein (10.80 Mb$10.85 \mathrm{Mb})$ and Ras association domain-containing protein $10(11.40-11.41 \mathrm{Mb})$ were also identified for having over a three-fold male-biased expression pattern. Ras association domain family proteins have been implicated as tumor suppressors [47-49]. Therefore, upregulation of these genes could suppress primordial germ cell proliferation leading to maleness. 
Lastly, it is possible that there could be Y-specific genes that were not captured in our study, because the reference genome that the reads were aligned to is a homozygous clonal XX individual.

\section{Conclusions}

Inversions have been well-documented in sex-chromosome evolution and are one possible mechanism for resolving sexually antagonistic selection near the novel sexdeterminer through a reduction in recombination [4]. This study revealed an $8.8 \mathrm{Mb}$ block of differentiation between males and females. The variety of evidence presented here is most consistent with the presence of an inversion. The decay of genes and overall level of differentiation indicate that this region has substantially reduced recombination. We have also documented an accumulation of SNPs causing functional alterations within this region, as would be expected for a genomic region suffering both the deleterious effects of Muller's Ratchet and accumulation of deleterious alleles hitchhiking to fixation with advantageous alleles. The transcriptome data indicates that genes inside the proposed inversion show significant enrichment for female-biased expression. These data suggest that $O$. niloticus has not yet evolved complete dosage compensation. Future functional studies are needed to identify the master sex-determination gene(s) within this region. Further research on cichlid sex determination will help unravel the underlying sex-determination network that underlies the rapid turnover of sex-determination mechanisms within teleosts.

\section{Methods}

\section{Genomic DNA pools}

All animal procedures were conducted in accordance with University of Maryland IACUC Protocol \#R-10-73. The fish sequenced are 3rd generation descendants of fish collected from a commercial tilapia farm in Amherst, Massachusetts USA. Individuals from two related labraised families were sacrificed and visually inspected for the presence testes or ovaries to determine the sex of each fish. Fish with ambiguous or immature gonads were excluded from the study. DNA was extracted from fin clips using a standard phenol/chloroform protocol. To confirm the family identity we genotyped each individual for two sex-linked microsatellite markers selected from the Broad anchored tilapia assembly on linkage group 1 (MS1045 at 14.32 $\mathrm{Mb}$ and MS1141 at $15.53 \mathrm{Mb}) .33$ males and 20 females from family BYL078 and 25 males and 13 females from family BYL084 were selected for pooling. DNA from each individual was then quantified by Picogreen fluorescence on a BioTek FLx800 spectrophotometer and appropriate dilutions were made to ensure equal representation of each individual in the pooled samples. The pooled male (or female) DNA from each family was sheared to 500 bp using a Covaris shearer and indexed separately during library construction. Paired-end libraries for each family/sex were constructed for Illumina sequencing using the Illumina TruSeq DNA Sample Prep Kit (Illumina, San Diego, CA). The male (or female) libraries from each family were combined and each sex was sequenced in a separate lane on an Illumina HiSeq 2000. The male and female reads were deposited to NCBI with the accession numbers SRR1606298 and SRR1606304, respectively. Only reads passing the Illumina CASAVA filtering were retained.

Read qualities was checked with FASTQC [50]. Alignments to the $O$. niloticus anchored reference assembly [51] were performed with Bowtie 2 [52] using the -verysensitive setting (Additional file 5). The mean alignment rate was $90.12 \%$ in males and $90.67 \%$ in females (Separate values for each family are given in Additional file 5). Read alignments were filtered for a minimum mapping quality (MAPQ) of 20 before further analysis. Insert sizes were analyzed using Picard tools CollectInsertSizeMetrics package [53]. The aligned mean insert size was $188.76 \mathrm{bp}$ (standard deviation $=44.81 \mathrm{bp}$ ) for males and $167.62 \mathrm{bp}$ (standard deviation $=37.29 \mathrm{bp}$ ) for females. Variants were called using GATK [54].

\section{Genomic analysis}

Popoolation2 [55] was used to calculate $\mathrm{F}_{\mathrm{ST}}$ and Fisher's exact test on allele frequency differences between the male and female pools. Initial $\mathrm{F}_{\mathrm{ST}}$ results from the individually adapter-indexed families were very similar, so all subsequent analyses were performed on the combined male or female pool, including unassigned reads from the male and female lane which could not be assigned to a particular family.

A custom Perl script, Sex_SNP_finder_now.pl (available at https://github.com/Gammerdinger/sex-SNP-finder), was used to identify SNPs at intermediate frequencies in the male pools and were fixed or nearly fixed in female pools at the same position. Intermediate SNPs were defined as SNPs with a frequency between 0.3 and 0.7 within the male pool. Fixed or nearly fixed sites required a frequency less than or equal to 0.1 or greater than or equal to 0.9 within the female pool. We used a non-overlapping window of $10 \mathrm{~kb}$ to determine the density of these SNPs. The non-overlapping window did not include positions with coverage less than 10 reads in both sexes. The Sex SNP_finder_now.pl script outputs a tab-delimited file with the number of SNPs per window along with an Integrative Genomics Viewer file [56] that lists all SNPs that were fixed or nearly fixed in one designated pool and in intermediate frequency in the other.

We used SnpEff [30] to identify variants predicted to alter gene function. The SnpEff output was filtered to consider only the SNPs found using Sex_SNP_finder_now.pl. 
SnpSift [31] was used to extract out SNPs with similar effects and impacts. A complete list of genes within the proposed inversion can be found in Additional file 6 .

\section{Transcriptome analysis}

Gonads were dissected from individual larvae 28 days post-fertilization. The sex of each larvae was determined by genotyping microsatellite markers highly associated with sex. RNA from approximately 20 male or 20 female larvae was pooled and cDNA libraries were constructed using the Illumina TruSeq DNA Sample Prep Kit. Sequencing of these libraries yielded $\sim 392$ million reads for each male and female pool. Reads were aligned to the O. niloticus reference sequence with TopHat2 [57]. NCBI RefSeq annotations were used to guide the Cufflinks [58] assembly (-g) and Cuffdiff was used to was used to determine FPKM values for those gene models. The results were subsequently filtered to exclude gene models whose FPKM value was less than 0.05 in both males and females. Additionally, when comparisons between FPKM of the two sexes was carried out, if the FPKM value exceeded 0.05 in one sex and was zero in the other sex, it was considered an undefined bias favoring the sex with expression. Female-biased and male-biased gene models from inside and outside the proposed inversion were counted and statistical significance was looked for using $X^{2}$ with Yates' correction on a $2 \times 2$ contingency table. These male and female reads from the RNA-Seq experiment were deposited to NCBI with the accession numbers SRR1606274 and SRR1606273, respectively.

\section{Additional files}

Additional file 1: Putative functional mutations outside the proposed inversion. List of the genes outside the inversion that contain a stop codon or splice site alteration that was in intermediate frequency in males and fixed or nearly fixed in females. There were no start codon alterations meeting these requirements found outside of the proposed inversion.

Additional file 2: Missense mutations from the entire genome. List of the missense mutations from the entire genome and their locations which were in intermediate frequency in males and fixed or nearly fixed in females.

Additional file 3: Gene models with male-biased expression. Malebiased gene locations, male and female FPKM values and $\log _{2}$ ratio of male to female FPKM. Thick bold lines indicate groups of genes showing two-fold, three-fold or four-fold expression difference. The genes are ordered from highest male-bias to lowest male-bias. *A second gene model of XM_003437627.1 has a female-biased expression. ${ }^{* *}$ A second gene model of XM_003442371.1.1 has a female-biased expression.

Additional file 4: Gene models with female-biased expression. Female-biased genes locations, male and female FPKM values and $\log _{2}$ ratio of female to male FPKM. Thick bold lines indicate groups of genes showing two-fold, three-fold or four-fold expression difference. The genes are ordered from highest female-bias to lowest female-bias. *Two gene models of XM_003442373.1 have a female biased expression. ${ }^{* *}$ A separate gene model of XM_003437627.1 has a high male-biased expression. ${ }^{* * *} \mathrm{~A}$ second gene model of XM_003442371.1.1 has a female-biased expression.
Additional file 5: Bowtie2 alignment statistics. Alignment statistics for each sex within each family along with the alignment statistics for the pooled data after the families and unassigned reads were combined.

Additional file 6: List of genes inside proposed inversion. NCBI accession numbers and gene names for the genes identified within the proposed inverted region.

\section{Competing interests}

The authors declare that they have no competing interests.

\section{Authors' contributions}

WJG helped conceive the study and was involved in specimen collection, genotyping of specimens, quantifying DNA, computational analysis and drafting of the manuscript. MAC helped conceive the study, substantially contributed to the computational analysis and aided in drafting of the manuscript. EAA substantially aided in specimen collection and genotyping of specimens. RBR constructed the CDNA libraries and aided in drafting of the manuscript. TDK helped conceive the study, constructed the pooled DNA libraries, guided the analysis and helped draft the manuscript. All authors read and approved the final manuscript.

\section{Acknowledgements}

We wish to thank the National Science Foundation for providing computational space and support through Indiana University Pervasive Technology Institute on the National Center for Genome Analysis Support (NCGAS) Mason Computing Cluster. We also wish to thank Karen Carleton for her insightful comments and suggestions on the manuscript. This work was supported in part by the National Science Foundation under Grant Number DEB-1143920. Funding for Open Access provided by the UMD Libraries Open Access Publishing Fund.

\section{Author details}

${ }^{1}$ Department of Biology, University of Maryland, College Park, MD 20742, USA. ${ }^{2}$ Current address: Program in Genetics, North Carolina State University, Raleigh, NC 27695, USA.

Received: 16 July 2014 Accepted: 29 October 2014

Published: 17 November 2014

\section{References}

1. Charlesworth B: The evolution of sex chromosomes. Science 1991, 251:1030-1033.

2. Rice WR: The accumulation of sexually antagonistic genes as a selective agent promoting the evolution of reduced recombination between primitive sex chromosomes. Evolution 1987, 41:911-914.

3. Rice WR: Evolution of the $Y$ sex in animals: $Y$ chromosomes evolve through the degeneration of autosomes. Bioscience 1996, 46:331-343.

4. Lahn BT, Page DC: Four evolutionary strata on the human $\mathrm{X}$ chromosome. Science 1999, 286:964-967.

5. Hedrick PW: Genetic drift and effective population size. In Genetics of Populations. 4th edition. Sudbury, MA: Jones and Bartlett Publishers; 2011:187-245

6. Green M: Muller's Ratchet and the evolution of supernumerary chromosomes. Genome 1990, 33:818-824.

7. Bachtrog D: Y-chromosome evolution: emerging insights into processes of Y-chromosome degeneration. Nat Rev Genetics 2013, 14:113-124.

8. Mank JE: Sex chromosome dosage compensation: definitely not for everyone. Trends Genet 2013, 29:677-683.

9. Vicoso B, Bachtrog D: Progress and prospects toward our understanding of the evolution of dosage compensation. Chromosome Res 2009, 17:585-602.

10. Heard E, Disteche CM: Dosage compensation in mammals: fine-tuning the expression of the X chromosome. Genes Dev 2006, 20:1848-1867.

11. Lyon MF: Sex chromatin and gene action in the mammalian X-chromosome. Am J Hum Genet 1962, 14:135-148.

12. Bellott DW, Hughes JF, Skaletsky H, Brown LG, Pyntikova T, Cho T, Koutseva N, Zaghlul S, Graves T, Rock S, Kremitzki C, Fulton RS, Dugan S, Ding Y, Morton D, Khan Z, Lewis L, Buhay C, Wang Q, Watt J, Holder M, Lee S, Nazareth L, Rozen S, Muzny DM, Warren WC, Gibbs RA, Wilson RK, Page DC: Mammalian Y chromosomes retain widely expressed dosage-sensitive regulators. Nature 2014, 508:494-499. 
13. Cortez D, Marin R, Toledo-Flores D, Froidevaux L, Liechti A, Waters P, Grützner F, Kaessman H: Origins and functional evolution of $\mathrm{Y}$ chromosomes across mammals. Nature 2014, 508:488-493.

14. Koopman P, Gubbay J, Vivian N, Goodfellow P, Lovell-Badge R: Male development of chromosomally female mice transgenic for Sry. Nature 1991, 351:117-121.

15. Kikuchi K, Hamaguchi S: Novel sex-determining genes in fish and sex chromosome evolution. Dev Dyn 2013, 242:339-353.

16. Ross JA, Urton JR, Boland J, Shapiro MD, Peichel CL: Turnover of sex chromosomes in the stickleback fishes (Gasterosteidae). PLoS Genet 2009, 5:e1000391.

17. Kocher TD: Adaptive evolution and explosive speciation: the cichlid fish model. Nat Rev Genet 2004, 5:288-298

18. Ser JR, Roberts RB, Kocher TD: Multiple interacting loci control sex determination in lake Malawi cichlid fish. Evolution 2010, 64:486-501.

19. Roberts RB, Ser JR, Kocher TD: Sexual conflict resolved by invasion of a novel sex determiner in Lake Malawi cichlid fishes. Science 2009, 326:998-1001.

20. Parnell NF, Streelman JT: Genetic interactions controlling sex and color establish the potential for sexual conflict in Lake Malawi cichlid fishes. Heredity 2013, 110:239-246.

21. Cnaani A, Lee BY, Zilberman N, Ozouf-Costaz C, Hulata G, Ron M, D'Hout A Baroiller JF, D'Cotta H, Penman DJ, Tomasino E, Coutanceau JP, Pepey E, Shirak A, Kocher TD: Genetics of sex determination in tilapiine species. Sexual Dev 2008, 2:43-54.

22. Eshel O, Shirak A, Weller J, Hulata G, Ron M: Linkage and physical mapping of sex region on LG23 of Nile tilapia (Oreochromis niloticus). G3 2012, 2:35-42.

23. Lee BY, Hulata G, Kocher TD: Two unlinked loci controlling the sex of blue tilapia (Oreochromis aureus). Heredity 2004, 92:543-549.

24. Lee BY, Penman DJ, Kocher TD: Identification of a sex-determining region in Nile tilapia (Oreochromis niloticus) using bulked segregant analysis. Anim Genet 2003, 34:1-5.

25. Lee BY, Countanceau JP, Ozouf-Costaz C, D'Cotta H, Baroiller JF, Kocher TD: Genetic and physical mapping of sex-linked AFLP markers in Nile tilapia (Oreochromis niloticus). Marine Biotechnol 2011, 13:557-562.

26. Ezaz MT, Harvey SC, Boonphakdee C, Teale AJ, McAndrew BJ, Penman DJ: Isolation and physical mapping of sex-linked AFLP markers in Nile tilapia (Oreochromis niloticus L.). Marine Biotechnol 2004, 6:435-445.

27. Palaiokostas C, Bekaert M, Kahn MGQ, Taggart JB, Gharbi K, McAndrew BJ, Penman DJ: Mapping and validation of the major sex-determining region in Nile tilapia (Oreochromis niloticus L.) using RAD sequencing. PLOS One 2013, 8:e68389.

28. Lee BY, Lee WJ, Streelman T, Carleton KL, Howe AE, Hulata G, Slettan A, Stern JE, Terai $Y$, Kocher TD: A second-generation genetic linkage map of tilapia (Oreochromis spp.). Genetics 2005, 170:237-244.

29. Oliveira C, Wright JM: Molecular cytogenetic analysis of heterochromatin in the chromosomes of tilapia, Oreochromis niloticus (Teleostei: Cichlidae). Chromosome Res 1998, 6:205-211.

30. Cingolani P, Platts A, Wang LL, Coon M, Nguyen T, Wang L, Land SJ, Ruden DM, Lu X: A program for annotating and predicting the effects of single nucleotide polymorphisms, SnpEff: SNPs in the genome of Drosophila melanogaster strain w1118; iso-2; iso-3. Fly 2012, 6:80-92.

31. Cingolani $P$, Patel VM, Coon M, Nguyen T, Land SJ, Ruden DM, Lu X: Using Drosophila melanogaster as a model for genotoxic chemical mutational studies with a new program, SnpSift. Front Genet 2012, 3:35.

32. Fisher RA: The evolution of dominance. Biol Rev 1931, 6:345-368.

33. Chibalina MV, Filatov DA: Plant Y chromosome degeneration is retarded by haploid purifying selection. Curr Biol 2011, 21:1475-1479.

34. Zhou Q, Bachtrog D: Chromosome-wide gene silencing initiates $Y$ degeneration in Drosophila. Curr Biol 2012, 22:522-525.

35. Chen S, Guojie Z, Shao C, Huang Q, Liu G, Zhang P, Song W, An N, Chalopin D, Volff JN, Hong Y, Li Q, Sha Z, Zhou H, Xie M, Yu Q, Liu Y, Xiang H, Wang N, Wu K, Yang C, Zhou Q, Liao X, Yang L, Hu Q, Zhang J, Meng L, Jin L, Tian Y, Lian J, et al: Whole-genome sequence of a flatfish provides insights into ZW sex chromosome evolution and adaptation to a benthic lifestyle. Nat Genet 2014 46:253-260.

36. Mair GC, Abucay JS, Skibinski DOF, Abella TA, Beardmore JA: Genetic manipulation of sex ratio for the large-scale production of all-male tilapia, Oreochromis niloticus. Can J Fish Aquat Sci 1997, 54:396-404.

37. Lee BY, Kocher TD: Exclusion of Wilms tumour (WT1b) and ovarian cytochrome P450 aromatase (CYP19A1) as candidates for sex determination genes in Nile tilapia (Oreochromis niloticus). Anim Genet 2007, 38:85-86.

38. Massagué J: How cells read TGF- $\beta$ signals. Nat Rev Mol Cell Biol 2000, 1:169-178

39. Patmore DM, Welch S, Fulkerson PC, Wu J, Choi K, Eaves D, Kordich JJ, Collins $\mathrm{MH}$, Cripe TP, Ratner N: In vivo regulation of TGF- $\beta$ by $R$-Ras 2 revealed through loss of the RasGAP protein NF1. Cancer Res 2012, 72:5317-5327.

40. Rhee JS, Lee YM, Raisuddin S, Lee JS: Expression of R-ras oncogenes in the hermaphroditic fish Kryptolebias marmoratus, exposed to endocrine disrupting chemicals. Comp Biochem Physiol Part C Toxicol Pharmacol 2009, 149:433-439.

41. Trukhina AV, Lukina NA, Wackerow-Kouzova ND, Smirnov AF: The variety of vertebrate mechanisms of sex determination. Biomed Res Int 2013, 2013:587460.

42. MOTIF. http://www.genome.jp/tools/motif/.

43. Swain A, Narvaez V, Burgoyne P, Camerino G, Lovell-Badge R: Dax1 antagonizes Sry action in mammalian sex determination. Nature 1998 391:761-767.

44. Gallardo TD, John GB, Shirley L, Contreras CM, Akbay EA, Haynie JM, Ward SE, Shidler MJ, Castrillon DH: Genomewide discovery and classification of candidate ovarian fertility genes in the mouse. Genetics 2007, 177:179-194.

45. Mohammed H, D'Santos C, Serandour AA, Ali HR, Brown GD, Atkins A, Rueda OM, Holmes KA, Theodorou V, Robinson JLL, Zwart W, Saadi A, Ross-Innes CS, Chin SF, Menon S, Stingl J, Palmieri C, Caldas C, Carroll JS: Endogenous purification reveals GREB1 as a key estrogen receptor regulatory factor. Cell Reports 2013, 3:342-349.

46. Ohe K, Lalli E, Sassone Corsi P: A direct role of SRY and SOX proteins in pre-mRNA splicing. Proc Natl Acad Sci U S A 2002, 99:1146-1151.

47. Dammann R, Li C, Yoon JH, Chin PL, Bates S, Pfeifer GP: Epigenetic inactivation of a RAS association domain family protein from the lung tumour suppressor locus 3p21.3. Nat Genet 2000, 25:315-319.

48. Burbee DG, Forgacs E, Zöchbauer-Müller S, Shivakumar L, Fong K, Gao B, Randle D, Kondo M, Virmani A, Bader S, Sekido Y, Latif F, Milchgrub S, Toyooka S, Gazdar AF, Lerman MI, Zabarovsky E, White M, Minna JD: Epigenetic inactivation of RASSF1A in lung and breast cancers and malignant phenotype suppression. J Natl Cancer Inst 2001, 93:691-699.

49. Shivakumar L, Minna J, Sakamaki T, Pestell R, White MA: The RASSF1A tumor suppressor blocks cell cycle progression and inhibits cyclin D1 accumulation. Mol Cellular Biol 2002, 22:4309-4318.

50. FASTQC. http://www.bioinformatics.babraham.ac.uk/projects/fastqc/.

51. Brawand D, Wagner CE, Li Yl, Malinsky M, Keller I, Fan S, Simakov O, Ng AY, Lim ZW, Bezault E, Turner-Maier J, Johnson J, Alcazar R, Noh HJ, Russell P, Aken B, Alföldi J, Amemiya C, Azzouzi N, Baroiller JF, Barloy-Hubler F, Berlin A, Bloomquist R, Carleton KL, Conte MA, D'Cotta HD, Eshel O, Gaffney L, Galibert F, Gante HF, et al: The genomic substrate for adaptive radiation in African cichlid fish. Nature 2014, 513:375-381.

52. Langmead B, Salzberg SL: Fast gapped-read alignment with Bowtie 2. Nat Methods 2013, 9:357-359.

53. Picard. http://broadinstitute.github.io/picard/

54. DePristo MA, Banks E, Poplin RE, Garimella KV, Maguire JR, Hartl C, Philippakis AA, del Angel G, Rivas MA, Hanna M, McKenna A, Fennell TJ, Kernytsky AM, Sivachenko AY, Cibulskis K, Gabriel SB, Altshuler D, Daly MJ: A framework for variation discovery and genotyping using next-generation DNA sequencing data. Nat Genet 2011, 43:491-498.

55. Kofler R, Pandey RV, Schlötterer C: PoPoolation2: identifying differentiation between populations using sequencing of pooled DNA samples (Pool-Seq). Bioinformatics 2011, 27:3435-3436.

56. Thorvaldsdóttir H, Robinson JT, Mesirov JP: Integrative Genomics Viewer (IGV): high-performance genomics data visualization and exploration. Brief Bioinform 2012, 14:178-192.

57. Kim D, Pertea G, Trapnell C, Pimentel H, Kelley R, Salzberg SL: TopHat2: accurate alignment of transcriptomes in the presence of insertions, deletions and gene fusions. Genome Biol 2013, 14:R36.

58. Trapnell C, Hendrickson DG, Sauvageau M, Goff L, Rinn JL, Pachter L: Differential analysis of gene regulation at transcript resolution with RNA-seq. Nat Biotechnol 31:46-53.

doi:10.1186/1471-2164-15-975

Cite this article as: Gammerdinger et al:: Structure and decay of a proto-Y region in Tilapia, Oreochromis niloticus. BMC Genomics 2014 15:975. 